УДК 94(575.4):625.1

ББК 63.3(5Тур) +39.2

\title{
Железнодорожное строительство в стратегии Российской империи по освоению Туркестана
}

\author{
И.Б. Бочкарева
}

Алтайский государственный университет (Барнаул, Россия)

\section{Railway Construction in the Russian Empire Strategy for Turkestan Development}

I.B. Bochkareva

Altai State University (Barnaul, Russia)

С присоединением к Российской империи обширных территорий Туркестана перед центральной и местной администрацией встали задачи налаживания управления регионом, обеспечения безопасности в свете соперничества с Великобританией за сферы влияния во Внутренней Азии, а также его экономического освоения, чтобы новая колония приносила империи в перспективе выгоду не только военно-стратегического характера. Необходимым условием закрепления России в Туркестане и его модернизации должно было стать создание сети коммуникаций, отвечающих требованиям формирующегося индустриального общества (железные дороги, пароходы, телеграф и др.). Вместе с тем железнодорожное строительство в Туркестане: его темпы, характер финансирования, маршруты дорог было обусловлено приоритетами политики России в регионе, среди которых военно-стратегические соображения явно доминировали над экономическим развитием. Однако, построив Закаспийскую, а затем Ташкентскую железные дороги, государство, еще не имея к началу XX в. сложившейся стратегии экономического освоения Туркестана, выступило в роли актора экономической модернизации края. Дороги стали средством экономической привязки Туркестана к России, а также одним из факторов оформления стратегии экономического развития региона в интересах метрополии, превращении его в базу хлопководства для нужд российской промышленности.

Ключевые слова: Российская империя, Туркестан, Закаспийская военная железная дорога, Ташкентская дорога, модернизация.

DOI 10.14258/izvasu(2019)5-04
With the annexation of vast territories of Turkestan to the Russian Empire to Central and local administration took up the task of establishing the control region, ensuring the security in the light of the rivalry with Britain for influence in Inner Asia and its economic development to a new colony brought the Empire in the long term benefit not only military-strategic. A necessary condition for the consolidation of Russia in Turkestan and its modernization was to create a communications network that meet the requirements of the emerging industrial society: Railways, steamers, telegraph. At the same time, the railway construction in Turkestan, its pace, financing, road routes were determined by the priorities of Russia's policy in the region, among which militarystrategic considerations clearly dominated over economic development. However, constructing the TransCaspian Railway, and then Tashkent Railway, the state, not with the beginning of the 20th century Turkestan economic development current strategy, acted as an actor of the region economic modernization. Railways became a means of economic binding of Turkestan to Russia, as well as one of the factors in the formation of the economic development strategy of the region in the metropolis interests, which consisted in its transformation into a cotton base for the needs of Russian industry.

Key words: Russian Empire, Turkestan, Trans-Caspian Military Railway, Tashkent Railway, modernization.

\footnotetext{
*Исследование выполнено за счет гранта Российского научного фонда (проект №19-18-00180).
} 
Необходимость создания современных средств коммуникации между Туркестаном и Россией осознавалась на всех уровнях имперской администрации после присоединения региона. Сдерживающим фактором в этом отношении выступало позиционное положение Туркестана, которое характеризуется глубокой континентальностью, замкнутой гидросистемой и отсутствием выхода в мировой океан ${ }^{1}$. В этих условиях железные дороги стали единственным способом налаживания современной транспортной коммуникации метрополии с колонией. В современных работах по истории железнодорожного строительства в Туркестане предметом анализа, как правило, становилась история строительства Закаспийской железой дороги, первой в крае $[1,2]$. При этом авторы неизменно отмечают положительный эффект железнодорожного строительства на экономическое развитие региона, что закономерно, так как взаимосвязь между железными дорогами и складыванием индустриального общества можно уже считать аксиомой. Однако в Туркестане логика железнодорожного строительства в имперский период не была столько прямо обусловлена экономическими факторами. В этой связи мы попытаемся проанализировать взаимосвязь между приоритетами политики России в регионе и строительством железных дорог.

В 1860-1870-е гг. в заинтересованных в развитии торговли с Центральной Азией кругах российского общества (например, среди оренбургского купечества) и на разных уровнях российской администрации активно обсуждался вопрос о строительстве дороги в Туркестан. Магистральная идея дискурса о железнодорожном строительстве в регионе заключалась в том, что дорога должна пройти в направлении от Оренбурга до Ташкента. В пользу этого работали следующие факторы: 1) караванный торговый путь, исторически сложившийся в этом же направлении, что само по себе свидетельствовало об экономической целесообразности маршрута; 2) территория от Ташкента вдоль Сырдарьи и далее от Арала на Оренбург была равнинной и не создавала особых проблем для проектирования и строительства дороги; 3) значение Ташкента как административного центра края и основного центра транзитной торговли в регионе.

За это время было подано около 40 проектов и рекомендаций, преимущественно по инициативе «снизу», со стороны отдельных предпринимателей, профессиональных и научных сообществ [3]. Основной интерес, лежащий в основе этих проектов, заключался создании условий для более вы-

${ }^{1}$ Две основные реки Центральной Азии Амударья и Сырдарья впадают в Аральское море, т.е. имеют внутренний сток и не могут быть использованы как водные пути для связи с европейской частью России и Сибирью. годной торговли с Туркестаном. Вместе с тем большинство проектов имело слабую техническую сторону, не опиралось на соответствующие изыскания на местности и, как правило, по этой причине отклонялось. Со стороны администрации активным сторонником строительства железной дороги в Туркестан был первый генерал-губернатор Туркестанского края К. Кауфман. По его поручению генерал-майор саперных войск К.С. Безносиков провел в 1873 г. исследования на местности и подготовил, пожалуй, наиболее технически обоснованный на тот момент проект железной дороги из Оренбурга в Ташкент. Целесообразность этого направления подтвердили научные экспедиции, организованные в 1877, 1878, 1879 гг. приказом правительства Российской империи для определения лучших направлений центральноазиатской железной дороги [3]. Таким образом, на протяжении 1870-х гг. вопрос о железной дороге до Туркестана постоянно актуализировался, и концу десятилетия сложился консенсус относительно направления дороги, была собрана необходимая техническая информация, но решения о строительстве так и не было принято. Развитие торговли с Туркестаном и коммерческая выгода от строительства дороги на тот момент оказались для правительства не достаточно мотивирующими факторами, чтобы выделить из казны деньги на столь масштабный и протяженный инфраструктурный проект. Правительство предпочитало вкладывать средства и поддерживать частные проекты по развитию железнодорожной сети европейской части России.

Как известно, первую железную дорогу в регионе без длительных предварительных обсуждений начали строить в 1880 г. совсем в другом направлении, в Закаспийской области, от Михайловского залива Каспийского моря до Кызыл-Арвата. Мотивом принятия решения о строительстве Закаспийской железной дороги стали сугубо военно-стратегические соображения. В связи со второй англо-афганской войной 1878-1880 гг., которая привела к превращению Афганистана в британский протекторат, российское руководство, чтобы не допустить расширения британского влияния на север, решило ускорить процесс присоединения туркменских племен.

Строительство железной дороги планировалось как часть подготовки и проведения второго ахалтекинского похода 1880 г. под руководством М.Д. Скобелева с целью взятия Геок-Тепе. По дороге должны были подвозиться боеприпасы и продовольствие для российской армии. Однако дорога от Михайловского залива до Кызыл-Арвата не успела сыграть отводимой ее роли в успехе похода М.Д. Скобелева, так как была закончена только в ноябре 1881 г., а главная крепость туркмен-текинцев Геок-Тепе была взята уже 12 января 1881 г., 
а 18 января - Ашхабад. Вместе с тем уже в ходе похода стали высказывать мысль о необходимости продолжения дороги до Ашхабада.

В конечном итоге строительство Закаспийской военной железной дороги (ЗВЖД) происходило в три этапа с перерывами, по мере того, как российская армия продвигалась на юго-восток вдоль хребта Копетдаг и присоединяла территории проживания туркменских племен. Участок дороги от Михайловского залива до Кызыл-Арвата начали строить в ноябре 1880 г. и закончили в ноябре 1881 г.; второй участок - от Кызыл-Арвата через Ашхабад и Мерв в Чарджоу - с апреля 1885 г. по декабрь 1886 г.; с возведением моста через Амударью дорогу довели до Самарканда в сентябре 1888 г. [1].

Мы не будем здесь останавливаться на технической стороне строительства ЗВЖД, которая достаточно подробно описана в литературе и является примером многих достижений инженерно-строительной мысли своего времени $[2,4]$. Дорога на всех этапах ее строительства рассматривалась российской администрацией как инструмент обеспечения стратегических интересов империи в регионе: удержания Туркестана в сфере влияния России и создания противовеса Великобритании. Так, решение о строительстве второго участка железной дороги от Кызыл-Арвата до Чарджуя было принято, когда уже шли российско-британские переговоры о делимитации северо-западного участка границы между Афганистаном и Туркестаном, осложненные военным столкновением российского и афганского отрядов в Пендинском оазисе в 1885 г. В свете российских военно-стратегических интересов ЗВЖД, проходя параллельно линии границы, особенно на участке от Мерва до Чарджуя, позволяла повысить степень безопасности этих территорий в случае возможной попытки Великобритании продвинуться в сферу российского влияния.

С. Горшенина, рассматривая вопрос о влиянии Закаспийской железной дороги на образ русского Туркестана во Франции, отмечает, что «все наблюдатели подчеркивали её важное значение в настоящем в качестве решающего фактора в подавлении региона Российской империей», а в условиях англо-российского противостояния в Центральной Азии и как залог успешного наступления на Индию [5, c. 227].

С начала строительства ЗВЖД находилась в ведении военного министерства и обсуживалась офицерами и рядовым составом двух Закаспийских железнодорожных батальонов, что само по себе говорило об ее целевом назначении. В сентябре 1883 г. для подробного ознакомления с эксплуатацией построенного на тот момент первого участка железнодорожного пути и разработки мер по более успешному его использованию была образована Комиссия под председательством начальника штаба войск Закаспийской области, генерал-лейтенанта Мейера. Комиссия пришла к выводу, что «данный железнодорожный путь не может иметь никакого торгового или коммерческого значения» [1, с. 114]. Это заключение, как нам представляется, на тот момент было вполне обоснованным, и не только потому, что российская власть изначально не преследовала коммерческие интересы при строительстве данной дороги, но и потому, что она не проходила через исторически сложившиеся в Туркестане экономические центры и крупные земледельческие оазисы, способные поставить на российский рынок товары в достаточном для перекрытия транспортных издержек объеме. Ситуация стала меняться, когда железная дорога была доведена через Бухару до Самарканда - города крупнейшего в Туркестане оазиса долины реки Зеравшан. С этого времени ЗВЖД стала играть роль, которую железные дороги сыграли в процессе экономической модернизации: увеличились объемы товарооборота между Туркестаном и европейской частью России, начался процесс специализации сельского хозяйства региона, ориентированного на рынок. Закаспийская дорога стала фактором постепенной трансформации экономической системы региона по колониальной модели в сырьевую базу для развивающейся российской промышленности и рынок сбыта промышленных товаров.

Согласно статистике Сырдарьинской области Туркестанского края уже через год после того, как железная дорога была доведена до Самарканда, кардинально изменился характер товарных перевозок между Туркестаном и европейской частью России. Так, например, хлопок, наиболее востребованный на российском рынке сырьевой продукт из Туркестана, раньше свозили в Ташкент из Ферганской долины и Самарканда для отправки по караванному пути до Оренбурга. В 1889 г. основная масса хлопка из Ташкента (360 тыс. пудов) была вывезена в Россию через Самарканд, а через Оренбург только 9 тыс. пудов, т.е. в 43 раза меньше [6, с. 118-119]. Данные за 1890 г. подтверждают сложившееся соотношение в направлениях и объемах вывоза хлопка [7, с. 76].

С установлением железнодорожного сообщения между земледельческими оазисами Туркестана и Россией гужевые перевозки на верблюдах по Оренбургскому торговому тракту оказались в состоянии кризиса. В обзоре по Сырдарьинской области за 1890 г. отмечается: «Оренбургский торговый тракт как бы замер <...> и возчики киргизы понизили до минимума провозную плату за верблюда» [7, с. 73]. Регулярность поездов, страхование грузов, значительное сокращение времени доставки товаров до потребителя, возможность более бы- 
строго оборота капиталов и получения прибыли обусловливали выбор предпринимателей в пользу железной дороги. В 1889 г. путешествие по железной дороге от Санкт-Петербурга через Тифлис и Баку до Самарканда занимало семь с половиной дней, в то время как дорога по почтовому тракту только от Оренбурга до Ташкента требовала 25 дней [5, с. 265], а доставка товаров на верблюдах - дватри месяца.

К 1898 г. была построена железная дорога от Самарканда до Андижана с ответвлением на Ташкент, подключившая к железнодорожному сообщению Ферганскую долину, которая являлась основным поставщиком хлопка. На следующий год Закаспийская военная железная дорога была переименована в Среднеазиатскую железную дорогу르 и передана из Военного министерства в ведение Министерства путей сообщения, что, как представляется, дополнительно подтверждало сложившуюся к этому времени коммерческую значимость дороги над ее стратегическим значением, которое, впрочем, тоже не отменялось. Вместе с тем Среднеазиатская дорога не позволяла в полной мере решать задачи поступательного развития торговли и интеграции Туркестана в российскую экономику, поскольку имела свои слабые стороны. Помимо высоких текущих затрат на содержание дороги ${ }^{3}$, значительные неудобства в процессе транспортировки доставляло то, что дорога не была связана с общероссийской железнодорожной сетью, поэтому часть пути и пассажиры, и грузы должны были пройти морским путем, по Каспийскому морю от Красноводска до Баку.

На конец 1890-х гг. приходится пик железнодорожного строительства в имперской России. С 1896 по 1900 г. было построено 16204 км железных дорог, что почти в четыре раза превышало германский показатель и в восемь раз - французский [10, с. 47]. Стараниями министра финансов С.Ю. Витте железнодорожное строительство, причем на средства казны, стали воспринимать как необходимое условие решения государственной стратегической цели: индустриализации российской экономики и развития капитализма, а также как способ «скрепления» всей территории необъятной страны в стратегическом и экономическом отношении [10, с. 47].

${ }^{2}$ В имперский и советский периоды территория Туркестана в географическом отношении называлась Средняя Азия, что нашло отражение в названии общественных институтов. В настоящее время более распространенным является наименование Центральная Азия по западной традиции.

${ }^{3}$ Хотя валовый доход Закаспийской дороги рос, расходы на текущее и капитальное (строительство новых путей, станций, мостов) содержание дороги превышало доходы. В 1902 г. расходы превысили доходы на 1 млн 900 тыс., в 1906 г. на 5 млн 170 тыс. руб. [8, с. 413; 9, с. 477].
Закономерно, что в таких условиях вновь актуализировался вопрос о строительстве железной дороги между Ташкентом и Оренбургом. Как и в 1870-е гг., инициатива в постановке вопроса о строительстве дороги исходила «снизу», от городских дум Оренбурга, Ташкента, Нижнего Новгорода. В течение 1896-1897 гг. генерал-губернатор Туркестана А.Б. Вревский и другие руководители администрации края неоднократно обращались к министру финансов С.Ю. Витте и министру путей сообщения М.И. Хилкову с предложением строительства железной дороги Ташкент - Оренбург, аргументируя ее важность для интересов Российской империи [3]. Однако эти инициативы не встречали поддержки в правительстве в силу ограниченности финансов, так как государство строило Транссибирскую магистраль и ее составляющую - Китайско-Восточную железную дорогу.

Предложение А.Б. Вревского создать акционерное общество для привлечения частных инвесторов к строительству дороги также было отклонено, поскольку правительство в это время, наоборот, следовало курсу выкупа частных железных дорог в казну, так как не было удовлетворено условиями их работы ${ }^{4}$. Показательно, что в то же время правительство выделило средства на строительство железной дороги от Мерва до Кушки, руководствуясь сугубо стратегическими соображениями: на случай военных действий с Великобританией на афганской границе и необходимости сосредоточения там войск.

В конечном итоге вопрос о строительстве Ташкентской железной дороги, как отмечает В. Масальский, перешел в практическую плоскость после того, как военный министр Куропаткин в 1899 г. в письме к Витте выдвинул «в защиту этого проекта соображения стратегические» [4, с. 583]. 4 апреля 1990 г. император Николай II утвердил направление Оренбург - Ташкент новой железной дороги как предпочтительное. Дорога начала строиться в 1901 г. и была закончена к январю 1906 г. Политика в сфере железнодорожного строительства в Туркестане свидетельствует, что к на-

${ }^{4}$ В 1870-1880-е гг. правительство стремилось привлечь частные капиталы для интенсификации железнодорожного строительства. В этой связи оно гарантировало частным обществам чистый доход в размере 5\% на затраченный капитал. Поскольку большинство частных железнодорожных компаний были нерентабельны, государству приходилось доплачивать им по итогам года деньги для обеспечения гарантированного дохода. Примером может служить Митавская железная дорога. Так, в 1889 г. правление дороги запросило распоряжение Министерства путей сообщения для отпуска гарантий правительства в сумме 67321 руб. на уплату процентов по акциям и облигациям, приложив соответствующие финансовые документы $[11$, л. 1]. И это была стандартная практика. 
чалу XX в. российская политическая элита всерьез еще не рассматривала регион как объект приложения модернизационных усилий государства. Туркестан по-прежнему воспринимался преимущественно как приграничная с британской сферой влияния территория, которую нужно оборонять, а стратегические соображения оказывались решающими в принятии решений по строительству дорог.

Вместе с тем в строительстве железных дорог в регионе и заключалась основная роль государства в модернизационном процессе. Дорога Оренбург Ташкент стала еще одним стимулом ускорения процесса специализации и товарности сельского хозяйства региона. Как правило, в литературе в подтверждение приводится статистка объемов вывоза хлопка, которая имела позитивный характер, что в принципе было ожидаемо, учитывая спрос на это сырье со стороны текстильной промышленности. Хотелось бы отметить тот факт, что Ташкентская железная дорога, представляя собой более короткий путь связи Туркестана с центром России ${ }^{5}$ и, соответственно, была коммерчески более выгодный, нежели Среднеазиатская дорога, быстро стала доминировать в грузовых перевозках. В 1909 г. из области по Ташкентской дороге было вывезено 497 тыс. пудов хлопка, а по Среднеазиатской в европейскую часть России - 51 тыс. пудов [12, с. 112]. В 1913 г. это соотношение было 1 млн 133 тыс. к 204 тыс. пудов хлопка [13, с. 98-99].

Железные дороги играют роль своего рода «осей роста», обеспечивая концентрацию факторов производства в тех населенных пунктах, через которые проходят, либо выступают условием создания новых. Так как Ташкентская дорога проходила вдоль северного берега Аральского моря, то рядом со станцией «Аральское море» уже в 1907 г. образовался рабочий поселок на 1500 чел., специализирующийся на ловле рыбы [14, л. 21], а сама станция стала основным транзитным пунктом вывозы рыбы из региона в Россию. В 1909 г. через нее было вывезено 1 млн 964 тыс. пудов рыбы, почти в четыре раза больше, чем хлопка [12, с. 112].

Строительство Ташкентской дороги стало, как представляется, одним из факторов окончательного складывания стратегии экономического развития Туркестана, цель которой заключалась в превращении его в базу российского хлопководства.
Наиболее обоснованно эта стратегия была изложена в Записке главноуправляющего землеустройством и земледелием А.В. Кривошеина в 1912 г. после поездки в Туркестан. Для достижения поставленной цели государство, по его мнению, должно было осуществить серию модернизационных преобразований: обновить имеющиеся и построить новые оросительные системы для расширения площадей под посевы хлопка, улучшить организацию мелкого кредита для хлопководов путем создания кредитных товариществ, усилить агрономическую помощь $[15$, с. $358-359]$.

Железным дорогам также отводилась важная роль в реализации стратегии. Поскольку расширение посевов хлопка должно было происходить за счет сокращения посевов зерновых, зерно планировалось ввозить в Туркестан из соседней Семиреченской области и Западной Сибири. Для этого А.В. Кривошеин настаивал на ускорении постройки Семиреченской железной дороги от станции Арысь Ташкентской железной дороги до города Верный. Стратегия экономического развития Туркестана не была реализована на практике имперским правительством из-за начавшейся Первой мировой войны и Октябрьской революции, однако ее основные приоритеты легли в основу советской модернизации в регионе, включая строительство Туркестано-Сибирской железной дороги.

До начала XX в. политика России в Туркестане определялась доминированием стратегических интересов подчинения и закрепления территории и населения под её управлением над задачами экономической модернизации региона в интересах самой империи. Железнодорожное строительство в регионе оказалось в прямой зависимости от такой иерархии интересов. Первая в крае Закаспийская железная дорога должна была обеспечивать решение задачи подчинения и последующего обеспечения безопасности приграничных с Афганистаном территорий. Однако влияние Закаспийской и Ташкентской дорог на социально-экономическое развитие края во многом превосходило их стратегическое значение. Дороги стали средством экономической привязки Туркестана к России, фактором оформления хозяйственной специализации и развития рыночных отношений в регионе.

\section{Библиографический список}

1. Фурсов В.Н., Тестов В.Н. Возведение и функционирование Транскаспийской магистрали в $80-\mathrm{x}-$ нача-

${ }^{5}$ Путь от Ташкента до Москвы по Ташкентской железной дороге занимал четверо суток. ле 90-х гг. ХІХ в. // Научные ведомости Белгородского государственного университета. Серия: История. Политология. 2013. Вып. № 15 (158). 
2. Волков И.В. Железнодорожные коммуникации как фактор развития Русского Туркестана // Пространство и время. 2013. № 3(13).

3. Тогаева А.З. Дорога Ташкент - Оренбург и ее место в социально-экономической жизни Туркестана : автоpeф. дис. ... канд. ист. наук. Ташкент, 2010. URL: http:// netess.ru/3istoriya/269295-1-6251-575-09-togaeva-anoroyzayniddinovna-zheleznaya-doroga-tashkent-orenburgmesto-socialno-ekonomicheskoy-zhizni-tur.php.

4. Россия: полное географическое описание нашего отечества. Т. 19: Туркестанский край / сост. В.И. Масальский. СПб., 1913.

5. Горшенина С. Закаспийская железная дорога: стандартизация историко-литературных и иконографических репрезентаций русского Туркестана // Культурный трансфер на перекрестках Центральной Азии: до, во время и после Великого шелкового пути. Париж ; Самарканд, 2013.

6. Обзор Сыр-Дарьинской области за 1889 г. Приложение к всеподданнейшему отчету военного губернатора. Ташкент, 1890.
7. Обзор Сыр-Дарьинской области за 1890 г. Приложение к всеподданнейшему отчету военного губернатора. Ташкент, 1892.

8. Ежегодник Министерства финансов. Вып. 1905 года. СПб., 1906.

9. Ежегодник Министерства финансов. Вып. 1907/8 годы. СПб., 1909.

10. Акторы российской имперской модернизации (XVIII - начало XX в.): региональное измерение. Екатеринбург, 2016.

11. Российский государственный исторический архив (РГИА) Ф. 219. Оп. 1. Д. 9507.

12. Обзор Сыр-Дарьинской области за 1909 г. Ташкент, 1911.

13. Обзор Сыр-Дарьинской области за 1913 г. Ташкент, 1916.

14. РГИА Ф. 1396. Оп. 1. Д. 216.

15. Записка главноуправляющего землеустройством и земледелием о поездке в Туркестанский край в 1912 г. // Вопросы колонизации. 1913. № 12. 